\title{
Involvement in the criminal justice system among attendees of an urban mental health center
}

\author{
Allyson Anderson ${ }^{1 *}$, Silke von Esenwein ${ }^{1}$, Anne Spaulding $^{2}$ and Benjamin Druss ${ }^{1}$
}

\begin{abstract}
Background: Incarceration rates for people with serious mental illnesses are higher than the general population. However, research has been limited in regards to patterns of incarcerations for patients treated in public mental health settings. This study examines differences in lifetime imprisonment rates among patients of a U.S. urban Community Mental Health Center (CMHC) and national samples, within gender, race and education subgroups.

Findings: Participants were interviewed about their criminal history. Analyses compared lifetime incarceration history in this sample to a group with similar demographics. A majority (69.6\%) of the sample had been incarcerated and $34.0 \%$ had been incarcerated with a felony charge as compared with $2.7 \%$ expected for the control sample.

Conclusion: Within every racial and educational subgroup, incarceration rates were high compared to the general population. Though racial and educational factors partly explained added incarceration risk, presence of a serious mental disorder heightened the incarceration risk within all strata in this public sector setting.
\end{abstract}

Keywords: SMI; Incarceration; Urban; Education; Race; Risk Factors

Every year, approximately 1 million arrests in the United States involve a person with a Serious Mental Illness (SMI) (Fisher et al., 2011). Some literature has shown that sociodemographic factors (i.e., substance abuse history, lack of employment, or homelessness) at least partly explain elevated arrest rates among this population (Fisher et al., 2011; Greenberg et al., 2011; White et al., 2006; Draine et al., 2002). While research has examined the interaction of incarceration risk factors in the general population, there is no clear understanding how risk factors and SMI may influence criminal justice system (CJS) involvement in this population. An SMI diagnosis may increase the relative incarceration risk and CJS involvement for persons that are already facing a number of socio-economic challenges. For instance, in a study examining the National Longitudinal Surveys, Western and Pettit (2009) calculated cumulative risk of imprisonment from a national probability sample using longitudinal data and life-table methods that were displayed in terms of sex, race, and education. The goal of

\footnotetext{
* Correspondence: amande7@emory.edu

${ }^{1}$ School of Public Health, Health Policy and Management Department, Emory University, 1518 Clifton Rd NE, Atlanta, GA, 30322, USA

Full list of author information is available at the end of the article
}

the study was to understand the degree to which having an SMI in a public sector CMHC is a risk factor for incarceration over and above education, sex and race in comparison to the general population.

Western and Pettit concluded that there was a concentration of incarceration among low education and low-skilled black men. Though, the research addressed education, sex, and race as risk factors for incarceration, it did not examine SMI as an additional factor placing individual in the CJS and its potential influence on incarceration rates.

\section{Methods}

Patients participating in a trial of medical care management were recruited from an urban $\mathrm{CMHC}$ serving the poor and uninsured in metro Atlanta (Druss et al., 2010). Inclusion criteria for the project required that an individual had a SMI diagnosis and the capacity to consent. The current analysis used baseline data from the larger study. The participants were asked about their involvement in the CJS. They were asked to report any incarceration history and past offenses. Participants were not asked to distinguish between jail detention and prison. In order to approximate rates of incarceration in a prison (i.e., imprisonment), we created a new 
variable, "likely in prison". Persons who self-reported past incarceration as an adult and a felony charge were grouped into this variable. "Likely in prison" could thus be comparable to the variable used in Western and Pettit (2009) of "imprisonment".

The data was analyzed using the statistical software PASW Statistics 18 (formerly SPSS) (IBM SPSS, Inc., 2009). Observed and expected values by gender, race, and educational attainment were compared to national imprisonment statistics taken from Western and Pettit (2009), which they calculated using data from the National Longitudinal Survey of Youth (NLSY) 79. These values analyzed imprisonment by birth cohort. The NLSY 89 was chosen because this cohort, persons born 1955-1959, contained the average birth year of participants. Western and Pettit (2009) used life-table methods to generate cumulative risk of imprisonment based on race, gender, and educational attainment in the presence of mortality. Their analysis provided a national rate comparison and expected values were calculated for each group from the sample data. Chi-square tests were performed to test the significance of the difference between the observed and the expected incarceration rates provided by Western and Pettit (2009) using OpenEpi (Dean et al., 2006).

\section{Findings}

The sample consisted of 191 participants (see Table 1). Males represented $48.6 \%(n=93)$ of the sample. Participants were 46.94 years of age on average. One-hundred and forty-nine $(78.0 \%)$ participants self-identified as black and $33(17.3 \%)$ self-identified as white. The majority $(\mathrm{n}=128,67.0 \%)$ of participants had at least a high school education. Primary psychiatric diagnoses were depression $(\mathrm{n}=169,88.0 \%)$ and schizophrenia/schizoaffective disorder $(\mathrm{n}=80,41.9 \%)$. In addition, most participants $(\mathrm{n}=171$, $89.5 \%$ ) had an annual income of less than $\$ 10,000$; and 50 (26.2\%) of those individuals had no income at all.

A total of $156(81.7 \%)$ participants reported prior arrests, $133(69.6 \%)$ had been incarcerated in their lifetime, and $18(9.4 \%)$ were currently involved in legal proceedings. Participants self-reported felony offenses including violent crimes (i.e. murder, aggravated assault, and weapons offense) $(n=24,10.7 \%)$, property crimes $(n=22$, $9.8 \%)$, drug charges $(\mathrm{n}=13,5.8 \%)$, obstruction $(\mathrm{n}=4$, $1.8 \%)$, and DUI felony $(\mathrm{n}=2,0.9 \%)$. Misdemeanor charges included property crimes $(n=36,16.0 \%)$, crimes against public order $(\mathrm{n}=23,10.22 \%)$, DUI $(\mathrm{n}=20,8.89 \%)$, violent crimes (i.e. assault and battery) $(\mathrm{n}=14,6.22 \%)$, probation violation $(\mathrm{n}=3,1.33 \%)$ and sex crimes (i.e. prostitution and indecent exposure) $(\mathrm{n}=2,0.89 \%)$. A total of 65 (34.0\%) participants reported past incarceration as an adult and a felony charge-these were the participants who were "likely in prison".
Rates of "likely in prison" for each demographic group from the sample population were greater than the published expected lifetime risk of imprisonment (see Table 2). According to the NLSY89 statistic calculated by Western and Pettit (2009), twelve participants from the sample were expected to have a history of imprisonment. The sample displayed a significantly higher rate of imprisonment in comparison to the general population statistics $\left(\chi^{2}=41.9, \mathrm{df}=1, \mathrm{p}<0.01\right)$. Nearly $49 \%$ of black men in this sample were likely in prison in their lifetime, a risk ratio three times the national average of imprisonment for black men (14.09\%, $\mathrm{p}<0.01)$; and $22.2 \%$ of black women were likely in prison in their lifetime, which is 12 times the national average of imprisonment for black women $(1.79 \%, \mathrm{p}<0.01)$. White men and women were not expected to have any prior imprisonments in this sample. However, $40 \%(\mathrm{p}<0.01)$ of white men were likely imprisoned in comparison to the $2.3 \%$ lifetime imprisonment risk for white men; and $23.1 \%(\mathrm{p}<0.01)$ of white women in comparison to the $0.25 \%$ lifetime imprisonment risk.

In analyzing education in this population, formerly incarcerated individuals with a high school education $(n=51$, $66.2 \%)$ and those with some college or higher $(n=31$, $67.4 \%)$ had comparable incarceration rates. However, individuals with less than a high school education $(n=44$, 91.5\%) had significantly greater incarceration rates. The negative correlation between education and imprisonment indicated that individuals with more education were less likely to have an imprisonment history. Though, it was observed that individuals with SMI have a significantly greater risk of incarceration history than the general population; education may be a protective factor from imprisonment in this population.

\section{Discussion}

The rates of ever being incarcerated and/or likely imprisoned in this sample were significantly higher than the general population by race, gender, and educational level, by a factor of 5 . As expected, men had higher incarceration rates than women. Comparable to Western and Pettit (2009), men and those with less than a high school education have a greater risk of imprisonment than others within the sample population. Unlike other literature, race did not significantly affect incarceration risk since incarceration history was comparable between races, which may be attributable to the overrepresentation of African-Americans in the sample.

Incarceration rates were significantly higher in each demographic category. Thus, SMI may play a mediating role in incarceration within this population over and above race, education, and gender, possibly by placing them in these at-risk groups of being impoverished and less educated. In comparison to Western and Pettit's 
Table 1 Community mental health center sample descriptive statistics

\begin{tabular}{|c|c|c|c|c|c|c|c|c|}
\hline & \multirow[b]{2}{*}{ Total } & \multirow[b]{2}{*}{$\%$} & \multicolumn{2}{|c|}{ Never Incarcerated } & \multicolumn{2}{|c|}{ Ever Incarcerated } & \multicolumn{2}{|c|}{ Likely ever in prison } \\
\hline & & & $\mathrm{N}$ & $\%$ & $\bar{N}$ & $\%$ & $\mathrm{~N}$ & $\%$ \\
\hline Total & 191 & & 58 & 30.4 & 133 & 69.6 & 65 & 34.0 \\
\hline \multicolumn{9}{|l|}{ Gender } \\
\hline Male & 93 & 48.6 & 15 & 16.1 & 78 & 83.9 & 43 & 46.2 \\
\hline Female & 98 & 51.3 & 43 & 43.9 & 55 & 56.1 & 22 & 22.4 \\
\hline \multicolumn{9}{|l|}{ Age } \\
\hline Minimum & 24 & & 24 & & 24 & & 28 & \\
\hline Maximum & 74 & & 74 & & 64 & & 60 & \\
\hline Mean & 46.94 & & 48.66 & & 46.28 & & 46.54 & \\
\hline \multicolumn{9}{|l|}{ Age Group } \\
\hline $20-29$ & 5 & 2.6 & 1 & 20.0 & 4 & 80.0 & 1 & 20.0 \\
\hline $30-39$ & 19 & 9.9 & 6 & 31.6 & 13 & 68.4 & 7 & 36.8 \\
\hline $40-49$ & 98 & 51.3 & 25 & 25.5 & 73 & 74.5 & 33 & 33.7 \\
\hline 50-59 & 57 & 29.8 & 20 & 35.1 & 37 & 64.9 & 22 & 38.6 \\
\hline $60-69$ & 11 & 5.8 & 5 & 45.5 & 6 & 54.5 & 2 & 18.2 \\
\hline $70+$ & 1 & 0.5 & 1 & 100.0 & 0 & 0.0 & 0 & 0.0 \\
\hline \multicolumn{9}{|l|}{ Race } \\
\hline White & 33 & 17.3 & 9 & 27.3 & 24 & 72.7 & 11 & 33.3 \\
\hline Black & 149 & 78.0 & 47 & 31.5 & 102 & 68.5 & 51 & 34.2 \\
\hline Other & 9 & 4.7 & 2 & 22.2 & 7 & 77.8 & 3 & 33.3 \\
\hline \multicolumn{9}{|l|}{ Education Level } \\
\hline Less than high school & 60 & 31.4 & 15 & 25.0 & 45 & 75.0 & 26 & 43.3 \\
\hline High school diploma/GED & 82 & 42.9 & 27 & 32.9 & 55 & 67.1 & 28 & 34.1 \\
\hline Some college or greater & 46 & 24.1 & 15 & 32.6 & 31 & 67.4 & 10 & 21.7 \\
\hline Unknown & 3 & 1.6 & 1 & 33.3 & 2 & 66.7 & 1 & 33.3 \\
\hline \multicolumn{9}{|l|}{ Employment } \\
\hline Disability & 73 & 38.2 & 31 & 42.5 & 42 & 57.5 & 18 & 24.7 \\
\hline Unemployed & 94 & 49.2 & 18 & 19.1 & 76 & 80.9 & 42 & 44.7 \\
\hline Other & 24 & 12.6 & 15 & 62.5 & 9 & 37.5 & 5 & 20.8 \\
\hline \multicolumn{9}{|l|}{ Annual Income } \\
\hline No Income & 50 & 26.2 & 10 & 20.0 & 40 & 80.0 & 25 & 50.0 \\
\hline $1-5000$ & 58 & 30.4 & 15 & 25.9 & 43 & 74.1 & 18 & 31.0 \\
\hline 5001-10000 & 63 & 33.0 & 28 & 44.4 & 35 & 55.6 & 18 & 28.6 \\
\hline 10001-15000 & 12 & 6.3 & 2 & 16.7 & 10 & 83.3 & 3 & 25.0 \\
\hline$>15000$ & 5 & 2.6 & 2 & 40.0 & 3 & 60.0 & 1 & 20.0 \\
\hline \multicolumn{9}{|l|}{ Mental Health } \\
\hline Schizophrenia/schizoaffective disorder & 80 & 41.9 & 20 & 25.0 & 60 & 75.0 & 30 & 37.5 \\
\hline PTSD & 52 & 27.2 & 15 & 28.8 & 37 & 71.2 & 19 & 36.5 \\
\hline Depression & 168 & 88.0 & 54 & 32.1 & 114 & 67.9 & 55 & 32.7 \\
\hline Bipolar/Manic depression & 51 & 26.7 & 11 & 21.6 & 40 & 78.4 & 14 & 27.5 \\
\hline Anxiety disorder & 80 & 41.9 & 21 & 26.3 & 59 & 73.8 & 28 & 35.0 \\
\hline Alcohol abuse & 71 & 37.2 & 6 & 8.5 & 65 & 91.5 & 34 & 47.9 \\
\hline Drug Abuse & 77 & 40.3 & 8 & 10.4 & 69 & 89.6 & 34 & 44.2 \\
\hline Other Emotional conditions & 9 & 4.7 & 4 & 44.4 & 5 & 55.6 & 2 & 22.2 \\
\hline
\end{tabular}

Description of the sample population self-reported by participants from a CMHC in Atlanta, GA. 
Table 2 Observed Incarceration and Calculated Imprisonment versus Expected Lifetime Imprisonment Risk for CMHC Sample Population in Atlanta GA

\begin{tabular}{|c|c|c|c|c|c|c|c|c|c|}
\hline & & \multirow[t]{2}{*}{$\begin{array}{l}\text { Total in } \\
\text { CMHC }\end{array}$} & \multicolumn{2}{|c|}{$\begin{array}{l}\text { Incarceration in } \\
\text { CMHC population }\end{array}$} & \multicolumn{2}{|c|}{$\begin{array}{l}\text { Likely Ever } \\
\text { in Prison }\end{array}$} & \multirow{2}{*}{$\begin{array}{l}\text { NLSY89 Cumulative } \\
\text { Risk of Imprisonment } \\
\%\end{array}$} & \multirow{2}{*}{$\begin{array}{l}\text { Expected in CMHC } \\
\mathrm{N}\end{array}$} & \multirow[b]{2}{*}{ P-value } \\
\hline & & & $\mathbf{N}$ & $\%$ & $\mathbf{N}$ & $\%$ & & & \\
\hline \multirow[t]{4}{*}{ Black men } & Less than High school & 26 & 24 & 92.3 & 15 & 57.8 & 28.34 & 7 & \\
\hline & High school or equivalent & 23 & 18 & 78.3 & 9 & 43.5 & 12.64 & 3 & \\
\hline & Some college or higher & 19 & 17 & 89.5 & 9 & 47.4 & 4.97 & 1 & \\
\hline & All black men & 68 & 59 & 86.8 & 33 & 48.5 & $14.09^{*}$ & 10 & $<0.01$ \\
\hline \multirow[t]{4}{*}{ White men } & Less than High school & 7 & 5 & 71.4 & 3 & 42.9 & 8.57 & 1 & \\
\hline & High school or equivalent & 9 & 8 & 88.9 & 5 & 55.6 & 2.50 & 0 & \\
\hline & Some college or higher & 4 & 3 & 75 & 0 & 0 & 0.68 & 0 & \\
\hline & All white men & 20 & 16 & 80 & 8 & 40 & $2.30^{*}$ & 1 & $<0.01$ \\
\hline \multirow[t]{4}{*}{ Black women } & Less than High school & 24 & 14 & 58.3 & 7 & 29.0 & 4.93 & 1 & \\
\hline & High school or equivalent & 40 & 20 & 50 & 10 & 25.0 & 1.36 & 1 & \\
\hline & Some college or higher & 17 & 9 & 52.9 & 1 & 5.9 & 0.83 & 0 & \\
\hline & All black women & 81 & 43 & 53.1 & 18 & 22.2 & $1.79^{*}$ & 2 & $<0.01$ \\
\hline \multirow[t]{4}{*}{ White women } & Less than High school & 2 & 1 & 50 & 0 & 0 & 0.81 & 0 & \\
\hline & High school or equivalent & 5 & 5 & 100 & 3 & 60.0 & 0.30 & 0 & \\
\hline & Some college or higher & 6 & 2 & 33.3 & 0 & 0 & 0.09 & 0 & \\
\hline & All white women & 13 & 8 & 61.5 & 3 & 23.1 & $0.25^{*}$ & 0 & $<0.01$ \\
\hline
\end{tabular}

*These values for cumulative risk of imprisonment represent people 18-64 years of age.

Note: NLSY 1989 cohort is born 1955-1959. NLSY values were calculated by Western B \& Pettit B (2009). When comparing "Likely ever in prison" of the sample population to the NLSY expected imprisonment in this population, the $p$-value was $<0.01$. When analyzing imprisonment for each racial, gender group, the p-value was $<0.01$ for each group.

(2009) general population, incarceration is a greater risk for individuals with an SMI as they encounter CJS more than the general population. Historically, this population has had significantly lower educational attainment than individuals without mental disorders (Breslau et al., 2008) and about $90 \%$ of individuals in this sample lived below the 2005 U.S. poverty line (US Census Bureau, 2011). From Western and Pettit's conclusions, individuals with low education and low wages have a concentrated rate of incarceration. Though they may still experience incarceration or arrests at approximately the same rate across education statuses, educational attainment may protect this population from imprisonment. The combination of these risk factors in this population show that these individuals are not only poor and less educated, but they also have to manage a mental illness that may contribute to their encounters with the CJS.

Several limitations should be noted. First, the sample of patients was from only one public sector outpatient clinic, in a state with a high incarceration and poverty rates, limiting the generalizability of the findings (Pew Center on the States, 2012). Second, the dependent variable of incarceration was self-reported; respondents possibly misreported or underreported their involvement in the CJS. A large literature surveyed in Spelman (1994) examines the validity of self-reports of imprisonment in which infrequent offenders underreport criminal activity, frequent offenders exaggerate criminal involvement, and offenders are less likely to disclose crimes for serious offenses. However, participants' reports of past serious offenses were useful to analyze how this population is affected by criminal involvement and an issue that needs to be further addressed and understood. Lastly, Western and Pettit (2009) calculated these values for first incarceration as an age-specific cumulative risk of incarceration by age 35 and the average age of the study sample is 46.94 years. These limitations notwithstanding, incarceration history in this sample is significantly higher than in the general population lifetime risk of incarceration, even when compared to other high-risk sociodemographic strata. Promoting education and skills training in this population could potentially alter the outcomes of CJS involvement. In addition, it is important to further investigate the mediating roles of poverty and mental diagnosis over and above these demographic risks for incarceration. This study shows that having an SMI increases the likelihood of imprisonment for individuals regardless of race, gender, and education. However, the data cannot explain why SMI or poverty places these individuals at a greater risk or acknowledge diagnosis in relation to incarceration history.

Further study of incarceration in this underserved population will help explain and address the mechanisms by 
which mental illness places these individuals at greater risk of incarceration. Exploring the relationship among mental health diagnosis, treatment, crime, and poverty may help prevent future encounters with the CJS for these individuals.

\section{Abbreviations}

CMHC: Community Mental Health Center; SMI: Serious Mental Illness;

CJS: Criminal justice system; NLSY: National Longitudinal Survey of Youth.

\section{Competing interests}

The authors declare that they have no competing interests.

\section{Authors' contributions}

AA reviewed and categorized the criminal offenses self-reported by the study participants. AA and AS completed the data analysis for the study. All authors contributed to the writing and editing of the manuscript. All authors read and approved the final manuscript.

\section{Author details}

${ }^{1}$ School of Public Health, Health Policy and Management Department, Emory University, 1518 Clifton Rd NE, Atlanta, GA, 30322, USA. ${ }^{2}$ School of Public Health, Epidemiology Department, Emory University, 1518 Clifton Rd NE, Atlanta, GA, 30322, USA.

Received: 15 August 2014 Accepted: 3 February 2015

Published online: 25 February 2015

\section{References}

Breslau, J, Lane, M, Sampson, N, \& Kessler, RC. (2008). Mental disorders and subsequent educational attainment in a US national sample. Journal of Psychiatric Research, 42(9), 708-716. Retrieved from http://www.ncbi.nlm.nih. gov/pmc/articles/PMC2748981/.

Dean, AG, Sullivan, KM, \& Soe, MM (2006). OpenEpi: Open Source Epidemiologic Statistics for Public Health (Version 2.3.1) [Software]. Available from http://openepi.com/Menu/OE_Menu.htm

Draine, J, Salzer, MS, Culhane, DP, \& Hadley, TR. (2002). Role of social disadvantage in crime, joblessness, and homelessness among persons with serious mental illness. Psychiatric Services, 53(5), 565-573.

Druss, BG, von Esenwein, SA, Compton, MT, Rask, K, Zhao, L, \& Parker, RM. (2010). A randomized trial of medical care management for community mental health settings: The primary care access, referral, and evaluation (PCARE) study. American Journal of Psychiatry, 167, 151-159. doi:10.1176/appi.ajp.2009.09050691.

Fisher, WH, Simon, L, Roy-Bujnowski, K, Grudzinskas, A, Wolff, N, Crockett, E, \& Banks, S. (2011). Risk of arrest among public mental health services recipients and the general public. Psychiatric Services, 62(1), 67-72.

Greenberg, G, Rosenheck, RA, Erickson, SK, Desai, RA, Stefanovics, EA, Swartz, M, Keefe, RSE, McEvoy, J, \& Stroup, TS. (2011). Criminal justice system involvement among people with schizophrenia. Community Mental Health Journal, 47(6), 727-736. doi:10.1007/s10597-010-9362-9.

SPSS Inc. (2009). PASW Statistics for Windows, Version 18.0. Chicago: SPSS Inc.

Pew Center on the States (2012). 2012 Georgia public safety reform. Retrieved August 15, 2012 from http://www.pewtrusts.org/ /media/legacy/ uploadedfiles/pcs_assets/2012/PewGeorgiaSafetyReformpdf.pdf.

Spelman, W. (1994). Criminal Incapacitation. New York, NY: Springer.

U.S. Census Bureau. (2011). Social, economic, and housing statistics division: Poverty-Poverty thresholds 2005. Retrieved June 11, 2012, from https://www. census.gov/hhes/www/poverty/data/threshld/thresh05.html.

Western, B, \& Pettit, B. (2009). Technical report on revised population estimates and NLSY79 analysis tables for the Pew public safety and mobility project.

White, MC, Chafetz, L, Collins-Bride, G, \& Nickens, J. (2006). History of arrest, incarceration and victimization in community-based severely mentally ill. Journal of Community Health, 31(2), 123-135.

\section{Submit your manuscript to a SpringerOpen ${ }^{\circ}$ journal and benefit from:}

- Convenient online submission

- Rigorous peer review

- Immediate publication on acceptance

- Open access: articles freely available online

- High visibility within the field

- Retaining the copyright to your article

Submit your next manuscript at $\gg$ springeropen.com 